\title{
All Across the Universe: Bioethics Across Cultures
}

\author{
Michael Ashby
}

Published online: 29 October 2019

(C) Journal of Bioethical Inquiry Pty Ltd. 2019

This journal aspires to a global vision of bioethics. It has a distinct editorial category of "Global Bioethics," and its editorial team and board are globally engaged in both their vision and their lives. However, the Journal of Bioethical Inquiry is published by a global multi-national company, of European origin, and its editorial processes are firmly lodged in the western logical-positive tradition and peer review structures. Scrutiny of its publication and rejection record shows that most papers come from Australasia, North America, and Europe, and no doubt many authors from other regions, cultures, and traditions, would say they are under-represented. There are language barriers for sure and big differences in approach and writing styles. We do need to publish papers that have global interest and open up novel concepts, tell new stories, or describe innovative ways of analyzing ethical issues. In other words, papers that have some generalizable value to settings other than that of the authors in question. It is also clear that countries around the world are at different stages of development in their regulation

\footnotetext{
M. Ashby

Cancer, Chronic Disease and Sub-Acute Stream, Royal Hobart Hospital, Tasmanian Health Service, Hobart, Australia

M. Ashby ( $\bowtie)$

Medical Ethics and Death Studies, School of Medicine, College of Health and Medicine, University of Tasmania, Repatriation

Centre, 90 Davey Street, Hobart, TAS 7000, Australia

e-mail: michael.ashby@ths.tas.gov.au
}

and societal consideration of the conduct of science and health service delivery. They do this by attempting to implement core values and procedures of the global (but predominantly western) bioethics cannon but also by exploring their own political, religious, and philosophical traditions, and both these paths are represented in our short symposium in this issue, in Latin American, Middle Eastern, and Islamic settings.

These two avenues of enquiry might be considered crudely as either "ground up" or "top down." In the former approach, the work is done by exploring a particular tradition, and this often entails looking at politics, society, and culture, and both theology and philosophy, usually with a historical lens. Such a journey may end by attempting to see how a particular tradition then sits with regard to certain global bioethics "norms," especially when it comes to collisions between notions of autonomy and the collective. In the latter, "top down" approach, do we then work down from some notion of a universal set of principles and try to retro-fit them to a particular tradition? In the process, there may be significant clashes and struggles, especially for those countries that do not share the Judeo-Christian heritage. To what extent do we try to meet traditions where they are or seek to change them? If we do this, do we risk a kind of cultural arrogance? What happens if respecting a culture means accepting practices that violate universal human rights?

This author was recently struck by the story of Eleanor Roosevelt's chairing of the United Nations Commission on Human Rights in 1947-1948, as told in Ken 
Burns' remarkable documentary "The Roosevelts: An Intimate History."1 The horrors of a global war garnered world leaders, across the divides of the emerging Cold War, to set out basic human rights to which all could subscribe. Although many times honoured in the breach, this noble articulation, in the resulting declaration, of human worth and dignity, is the foundation of all attempts then and since, to set in place a basic normative ethical platform for the world. It is also, therefore, the foundation stone of bioethical principalism. It is an inspiring story of cooperation and creativity in the face of very deep difference, and the outcome if "only" words ("in the beginning was the word?"), rather than deeds, still has the value of setting the bar. The human challenge, as always, is that we usually know what we should do, but can we actually do it: the rhetoric-reality gap, the enacting of the fine principles.

Bioethics may have a normative core set of values, but the task of the field of enquiry, when it assumes a global perspective, is to explore this complex interface between local mores and the global norms. This is a difficult task, and one that needs ongoing work and human understanding, and this is the task of a journal like ours. Practical examples include how we accommodate customary law within a nation state's laws, lend support for those working on ethics in hostile political environments, challenging fundamentalism, campaigning against cultural practices that violate personhood and the body, and encouraging progressive humanitarian ideas, such as more enlightened drug laws and care, in all countries, especially in the west. All this needs to be done without western cultural imperialism or arrogance, honouring and learning from world traditions great and small. All the time recognizing that this is an ongoing task for which there is probably no end: bioethics is about difference, and this is our task, in this issue, and all others. Utopia is, of course, no place, but this does not mean that progress cannot be made, in the beginning was the word, and in this domain, understanding precedes action.

\footnotetext{
${ }^{1}$ The television documentary series "The Roosevelts: An Intimate History" (2014, Florentine Films: PBS) was based on a book of the same name written by Geoffrey Ward and Ken Burns (2014, Random House USA). The documentary was written by Ward and directed by Burns, and produced by Paul Barnes, Pam Tubridy Baucom, and Ken Burns (https://www.pbs.org/kenburns/the-roosevelts/about/overview/). At the time of writing the series was available to watch in Australia on the Netflix media streaming service.
}

In this issue we also offer you meditations on diet and identity, minorities and medicalization, disability and abortion, preimplantation genetic diagnosis (PGD), participation in dementia research, maturity assessment for minors, and doping in sport; as well as our regular Recent Developments legal column, a case study about privacy of psychotherapy treatment details; and a book review of Carina Fourie and Annette Rid's edited volume What Is Enough? Sufficiency, Justice, and Health.

In addition there are two commentaries, the first on enhanced interrogation, the second about the legal construct of a "right to try" in the United States, with regard to access to experimental drugs for terminally ill patients for whom all other therapies have failed. This editor, being a palliative care specialist, witnesses on a daily basis our individual and professional struggles with dying and the misery inflicted by false hope and last ditch treatments that often inflict more morbidity than quality of life, in the process distracting sick people and those who are close to them from a broader preparation for inevitable death, and sometimes undermining necessary palliative care. Most of the treatments concerned here are the subject of clinical trials that are being conducted for the very reason that the odds of a favourable outcome for a particular patient are not known but are usually not good. This is not to deny medical progress or disenfranchise the dying from potential benefit but rather to point out that there is a real danger that in many cases this may turn out to be a right that confers no benefit and may actually do harm. This last commentary takes the form of a response by Oliver Kim to Denise Meyerson's original paper, and Meyerson's reply to this. This is the sort of exchange that we have all too little of in these pages as a quarterly journal, with the time lags that this creates.

So to all our readers and authors, thank you, and please feel free to write, post, or respond as you see fit to any of these articles. May good thoughts lead to good deeds, and even when we can agree on what constitutes the good, may we narrow the gap between the different ways of getting there. 